\title{
Ulcerative colitis: definition, historical background, aetiology, diagnosis, natural history and local complications
}

\author{
F. T. DE Dombal \\ Lecturer in Surgery, University of Leeds
}

\section{Definition}

It has recently been argued that, since we do not know the basic cause of ulcerative colitis, formal definition of the disease is impossible and should not be attempted (Bargen, 1966). Nonetheless, the recent recognition that non-infectious colitis may be sub-divided into various disease entities-such as ulcerative colitis, Crohn's disease, ischaemic colitis and so on-has made it imperative to define each of these disease entities as closely as possible. The definition adopted in the present context is as follows:

\section{Ulcerative colitis}

An inflammatory disease of unknown origin, characterized clinically by recurrent attacks of bloody diarrhoea, and pathologically by a diffuse inflammation of the wall of the large bowel. The inflammatory changes spread proximally from the rectum; and are confined to (or most severe in) the colonic and rectal mucosa.

From this it will be apparent that the customary name by which this disease is known'ulcerative colitis'-is a thoroughly bad one, since ulceration is not a 'sine qua non' of the disease and since the disease usually involves colonic and rectal mucosa. Undoubtedly idiopathic diffuse mucosal proctocolitis', would be a more accurate descriptive term. Unfortunately however the terminology appertaining to various forms of colitis 'is already buried under the verbal debris of several centuries' (Crane, 1927); and since the term 'ulcerative colitis' possesses the twin merits of admirable brevity and wide usage, this is the term which will be adopted in the following description of the disease.

\section{Historical background}

In all probability we shall never know who first described ulcerative colitis; although the disease was first referred to by name in 1859 by Sir Samuel Wilks. Prior to that date, as far back as Roman times, various forms of non-contagious diarrhoea were described freely in the literature by such physicians as Aretaeus (A.D. 300), and the curiously aptly named Soranus (A.D. 117); and it has been suggested that in 1745 Prince Charles, the Young Pretender to the throne, suffered from ulcerative colitis and cured himself by adopting a milk-free diet (Wilson, 1961)!

Some years after Wilks (1859) first referred to the disease by name, the Surgeon General of the Union Army (describing the medical history of the American Civil War), also referred directly to 'ulcerative colitis'-and even produced photomicrographs showing the histologicab appearances, an outstanding technical achieve ment for the time (Crohn, 1962). Following these pioneer descriptions the pathological and clinica features of the disease were closely characterized, notably by Wilks \& Moxon (1875), Allching (1885) and Hale-White (1888). Gradually ulcer ative colitis became more widely recognized until in 1909, at a symposium of the Royaf Society of Medicine, no less than 300 cases had been collected from the various London hospitals. Since then the disease has consistently increased in popularity, until recent studies by Evans \& Acheson (1965) have suggested that it afflicts roughly 1 in 1000 of the general population.

\section{Aetiology}

Whilst it is unfortunately true to say that the aetiology of ulcerative colitis remains obscure, during the past few decades many attempts have been made to unravel this complicated problem. The most popular theories concerning the aetiology of ulcerative colitis can be listed as follows:

\section{Infection}

Even though ulcerative colitis had clearly been separated from the contagious forms of diarrhoea by the middle of the nineteenth century, until recently many workers refused to believe that this disease was not infectious in nature. Perhaps the most widely celebrated of these was Bargen, who 
in 1924 claimed to have isolated a diplococcus from the stools of patients suffering from ulcerative colitis-and even produced a vaccine against this diplococcus, which was claimed to be effective in such patients. Unfortunately in the fullness of time it became apparent that these claims were not entirely justified. Bargen's 'diplococcus' was shown to be almost certainly a harmless type of enterococcus found in the stools of vast numbers of the general population; and no real convincing evidence was forthcoming to suggest that the vaccine was effective in preventing attacks of colitis.

Since that date other authors have postulated that a number of organisms might be partly responsible for ulcerative colitis, including parasites, fungi and various viruses (Fradkin, 1937 ; Dragstedt, Dack \& Kirsher, 1941 ; Henderson, Pinkerton \& Moore, 1942 ; Victor, Kirsner \& Palmer, 1950). Unfortunately, however, further careful controlled studies have failed to uphold the claims of these various organisms to be the offending agents in causing ulcerative colitis. Thus there is little concrete evidence nowadays in support of any hypothesis proposing an infectious aetiology for ulcerative colitis.

\section{Mucinases}

In 1947 Meyer and his colleagues (Meyer, Gellhorn \& Prudden, 1947) proposed that ulcerative colitis might be due to destruction of the mucus lining the surface of the colon by enzymes, (which were termed mucinases), thus rendering the colon more susceptible to attack by bacterial and other agents. It was shown that stool concentration of lysozyme (an enzyme claimed to be capable of digesting colonic mucus), was higher in colitic patients than in normal controls, and that the stool concentration rose and fell during exacerbations and relapses of colitis.

It remained, however, far from certain that lysozyme was the cause of this disease, since the changes observed in lysozyme titre could very well have been the result instead. Finally this hypothesis fell into disrepute when it was shown (albeit in vitro) that lysozyme was incapable of dissolving or digesting human mucus (Glass et al., 1950).

\section{Allergy}

Despite the fact that some workers have succeeded in producing a type of delayed hypersensitivity reaction in the colon of the experimental animal (Rosenberg \& Fischer, 1964; Bicks \& Rosenberg, 1964), the position of allergens in the aetiology of ulcerative colitis is also somewhat uncertain at the present time. But it would be a serious omission to dismiss this subject without dealing in some detail with the potential allergen which has been most widely discussed during the last 40 years, namely cow's milk.

The idea that cow's milk might be in some way responsible for the development of ulcerative colitis was first emphasized by Andresen (1925, 1942). More recently as a result of studies by Truelove and his colleagues at Oxford, several additional facts have come to light which appear to support this hypothesis. These workers have shown that occasional patients with ulcerative colitis experience a remission of their disease when milk products are excluded from their diet, and suffer a relapse when they are re-introduced. Also it has been shown that the titre of antibodies to milk proteins in the circulation is significantly raised in colitic patients when compared with normal matched controls, and it has been further suggested that a significantly greater proportion of colitis patients have abandoned breast feeding in the 1st month of life than healthy matched controls (Truelove, 1961; Taylor \& Truelove, 1961 ; Acheson \& Truelove, 1961 ; Wright \& True love, 1965a, b).

However, in a subsequent controlled trial (Wright \& Truelove, 1965a), the benefit derived from a milk-free diet was only marginally significant despite the application of complex and elegant statistical tests; and it would require a much larger and more prolonged trial to confirm the value of this diet. As for the claim that circulating antibody titre to milk is raised both in colitic patients and in individuals who are weaned at an early age, this has both been supported and-conversely-denied (Dudek, Spiro \& Thayer, 1965), by other careful controlled studies.

There are several other pieces of evidence which argue that milk may not be the prime cause of ulcerative colitis. We in Leeds have tried to repeat Acheson and Truelove's survey concerning early weaning; but the majority of our patients could unfortunately not recall whether they were breast or bottle fed, and most of them seemed unable to find out! But we did discover that it is the clandestine custom of many maternity nurses to administer a feed of cow's milk every night (so as not to disturb the mother), to 'breast fed' infants born in hospital!

We may conclude that milk is unlikely to be the prime aetiological agent responsible for ulcerative colitis-although it may possibly play a secondary aetiological role, perhaps determining the occurrence of some subsequent relapses of the disease as suggested by Truelove (1961). 


\section{Psychological factors}

The controversy concerning Bargen's bacillus and the role of milk is as nothing compared with the polemic which has raged concerning the possible significance of psychological factors in the aetiology of ulcerative colitis. Indeed there is powerful evidence to suggest that emotional factors may be of some importance in maintaining or prolonging an existing attack of colitis. It is well known that feelings of anxiety or resentment may be accompanied by several changes in the colonic mucosa, comprising an increase in tone, in lysozyme secretion, and in intracolonic pressures; furthermore the mucosa may become hyperaemic and secrete a thick tenacious mucus (Grace, Wolf \& Wolff, 1951). These physiological studies have extreme importance, in that they provide powerful evidence in favour of the contention that attacks of colitis are more prolonged and severe in the presence of an adverse psychological reaction; and they provide powerful support for the inclusion in conservative management of this disease of a 'common sense' form of psychotherapy during an acute, troublesome attack (see p. 698).

However, there is very little evidence to suggest that the majority of patients suffering from ulcerative colitis have an inherently different emotional make-up from the remainder of the population. Of our own series of patients in Leeds less than $5 \%$ were attending or had attended a psychiatrist at any time time during their life. A further $9 \%$ when questioned about their reaction to colitis admitted that they considered their relapses of the disease to be related to emotional trauma-usually adding that they had previously been told that their colitis was caused by 'nerves'. The remainder of our patients seemed to us to be normal well-adjusted individuals who showed a natural interest in their disease. This finding has been supported by a similar carefully controlled study recently reported from the United States of America (Feldman et al., 1967).

Undoubtedly there are changes in the attitude to life of patients during severe attacks of colitis. They become depressed, morose and dependent upon their clinical attendants. But who would not be depressed at the prospect of ten or twelve bowel actions a day; and who would not become dependent upon a medical attendant whom one considered to be capable of alleviating this distressing symptom? If such depression and dependence are to be accepted criteria for a 'psychosomatic' disease, then one must carefully consider the claims of diseases such as peripheral arteriosclerosis, colonic cancer, hiatal hernia, congestive cardiac failure, and food poisoning to be psychosomatic diseases also!

\section{Autoimmunity}

The first studies suggesting that ulcerative colitis might be an autoimmune disease are widely attributed to Broberger \& Perlmann (1959)_although Cornelis (1958) had already suggested such a possibility. Broberger \& Perlmann (1959), using an extract of foetal colon in tissue culture, were able to show haemagglutinating antibodies to the colonic mucosa in no less than twenty out of thirty children with ulcerative colitis. It was still possible to argue that the changes which Broberger \& Perlmann had observed were occurring as a totally independent phenomenon, and were unrelated to the disease process of ulcerative colitis. But this argument was in part refuted by their further studies (Perlmann \& Broberger, 1963) showing that the leucocytes from patients with ulcerative colitis had a cytotoxic effect upon the foetal colon cells in tissue culture, an effect which was inhibited by pre-treatment with colon antigen. Broberger \& Perlmann's pioneer work has recently been confirmed and extended (Fink, Donnelly \& Jablokow, 1967 ; Watson, Quigley \& Bolt, 1966 ; de Dombal, 1967).

However, recent studies by Harrison (1965) and by Wright \& Truelove (1966) have shown that autoantibodies to colon can be demonstrated in only 15 or $20 \%$ of patients with ulcerative colitis ; and moreover there is little correlation between the clinical course of colitis and the incidence of circulating antibodies to colon. Thus it seems clear that some patients with ulcerative colitis do certainly develop circulating antibodies to their colonic mucosa cytoplasm; but the experimental evidence available has largely failed to show whether these antibodies arise as a cause or as an effect of the pathological changes which are occurring in the colon.

\section{Diagnosis}

\section{History and general examination}

It is surprising what scant attention is paid in the literature to this aspect of ulcerative colitis, presumably because the symptoms and the general physical findings are considered to be only too well known. The principal symptoms of ulcerative colitis are rectal bleeding and diarrhoea - which are present in nearly every case seen in an acute attack of the disease. Not so generally recognized is the fact that nearly two-thirds of patients during acute attacks suffer from a colicky type of abdominal pain; whilst less common symptoms are fever, weight loss, vomit- 
ing, tenesmus-and occasionally symptoms which occur as the result of systemic complications such as joint pain, iritis, or nodose skin lesions.

General physical examination of the colitic patient is usually unrewarding, but during severe acute attacks the patient may be emaciated, sallow in complexion, and showing evidence of anaemia and dehydration. Abdominal examination may reveal tenderness, localized muscular guarding and rigidity, and occasionally distension. However, it must be pointed out that there are considerable discrepancies in authoritative opinion regarding the reliability of these physical findings in severe acute ulcerative colitis; and this difficulty is increased by the widespread use of corticosteroids, which tend to mask the more florid signs of severe ulcerative colitis (and even on occasion to breed a false sense of security in the unwary physician). For this reason, in ulcerative colitis additional diagnostic procedures such as sigmoidoscopy and radiological studies assume an increased importance.

\section{Rectal examination including sigmoidoscopy}

It is difficult to over-rate the value of this examination in dealing with ulcerative colitis. A full rectal examination should be carried out on every new case of ulcerative colitis and certainly in any case in which the diagnosis is in doubt; sigmoidoscopy then being repeated from time to time to assess the progress of this disease. The facets of rectal examination which are relevant in this situation are several. First digital and proctoscopic examination is carried out, followed by a full and careful sigmoidoscopy. For any patient with new, or doubtful disease, rectal biopsy may then be performed; and a specimen of the patient's stools should be sent for culture.

Sigmoidoscopic appearances. The appearances generally accepted as being typical of ulcerative colitis are shown in Table 1 . However, there has recently been considerable dispute as to the ease and reliability with which these various signs can be recognized. Indeed in a recent survey from Leeds, Watts, Thompson \& Goligher (1966c) were able to identify only four characteristics of the rectal mucosa which could be recognized with any reliability, namely:

(1) The overall impression of normality or abnormality.

(2) The presence or absence of a vascular pattern.

(3) The presence or absence of contact bleeding.

(4) The presence or absence of oedema.

Moreover, as Matts (1961) has shown, quiescent ulcerative colitis is perfectly compatible with a normal sigmoidoscopic appearance showing none of these changes. His study emphasizes the need for additional rectal biopsy to be performed in any case where the diagnosis is in doubt, or where the sigmoidoscopic appearances indicate quiescent disease.

TABLE 1

Sigmoidoscopic appearances of ulcerative colitis

\begin{tabular}{|c|c|}
\hline Rectal wall & Lumen of bowel \\
\hline $\begin{array}{l}\text { Red (or very pale) mucosa } \\
\text { Absent vessel pattern } \\
\text { Contact bleeding } \\
\text { Granularity } \\
\text { Oedema } \\
\text { Ulceration } \\
\text { Absent or distorted valves } \\
\text { Rigidity } \\
\text { Polyps } \\
\text { Stricture } \\
\text { Carcinoma }\end{array}$ & $\begin{array}{l}\text { Mucopus } \\
\text { Free blood } \\
\text { Liquid faeces }\end{array}$ \\
\hline
\end{tabular}

\section{Radiological examination}

The classical method of radiological examination of the colon is undoubtedly by the barium enema technique; although more recently the value of plain $X$-ray plates of the abdomen has been emphasized, and selective mesenteric arteriographic method have been tried.

Barium enema examination. As long ago as 1912 the barium enema appearances of ulcerative colitis were described by Stierlin. Unfortunately, though there have been many additions since then to our knowledge of the abnormal findings in the colitic bowel on X-ray examination, there have been very few worth while attempts to evaluate the reliability and practical value of the various radiological signs described in this disease. In has, therefore, seemed relevant to us to examine our own experience in this respect in a highly critical manner, initially by means of careful 'observer variation' studies (Geffen et al., 1968 ; de Dombal et al., 1968). The findings in our own survey were somewhat disconcerting, in that although thirty or forty signs were listed for study at the start of the proceedings, there was no single radiological sign about which complete agreement could be reached between two independent observers!

A small group of radiological signs (Table 2) were, however, both frequently seen and reliably interpreted. These signs include many of the 'classical appearances' of ulcerative colitis, such as shortening and narrowing of the colon, absence of haustration, ulceration, and so on. We regard these signs as reliable; and would suggest that the diagnosis of ulcerative colitis 
made on a radiological basis should be determined on the presence or absence of these ten or eleven signs.

\section{TABLE 2}

Frequent, reliable radiological signs of ulcerative colitis seen on barium enema

$\left.\begin{array}{l}\text { Narrowing of bowel } \\ \text { Shortening of bowel } \\ \text { Decreased distensibility } \\ \text { Decreased bowel tone } \\ \text { Ulceration } \\ \text { Loss of haustration } \\ \text { Fine serration of bowel wall } \\ \begin{array}{l}\text { Polyps } \\ \text { Abnormal haustra } \\ \text { Longitudinal folds }\end{array} \\ \text { Double contour }\end{array}\right\}$ After evacuation

From Geffen et al. (1968).

Other radiological signs, described in the literature as being typical of ulcerative colitis, were shown on a detailed analysis to be almost certainly unreliable, since our two observers disagreed about their presence or absence more often than they were able to agree. Indeed there were a few signs in this category, such as spiculation, eccentric contour and the presence of a coarse reticular mucosal pattern, which were never agreed to be present at all! Occasionally one or other observer would claim that he saw such a sign; but in view of the failure to reach agreement in a single instance concerning the presence of these signs we must regard them as being utterly unreliable.

Plain X-ray abdominal examination. Simple radiological examination of the abdomen often reveals useful information in cases of ulcerative colitis. The gas ordinarily present in the large intestine is evident on a plain X-ray plate, and functions as an opaque medium to give an outline of the colon which may be recognized to be abnormal. The changes are most usually seen in the transverse colon if the plain film is taken with the patient lying supine. Occasionally further information is available, as when a cobblestone appearance indicates the presence of polyposis, or where a great widening of the colonic shadow indicates the occurrence of acute dilatation of the bowel. Hence the main value of plain abdominal $X$-ray examination is in the severe acute attack, both in the detection of the presence of colitis, and in the detection of the development of complications such as acute colonic dilatation. To be of use for this purpose it should be carried out both on admission of such patients, and thereafter every day or so until their acute attack has undergone remission.
Pathological diagnosis

It is not proposed to deal in any great detail with this difficult problem at this juncture; for considerable controversy exists concerning the pathological diagnosis of ulcerative colitis, and in particular the differentiation between ulcerative colitis and Crohn's disease involving the large bowel. Indeed this fascinating pathological distinction is worthy of discussion in its own right, and this has been undertaken elsewhere (Morson, 1968). Suffice it to say at this stage that ulcerative colitis almost without exception involves the rectum and spreads diffusely from the rectum for a variable distance proximally around the large bowel-whereas Crohn's disease is more apt to affect the colon and rectum on a segmental basis, the rectum frequently being completely normal in this latter complaint. The other cardinal pathological feature of ulcerative colitis is that the disease primarily involves the rectal and colonic mucosa; again in complete contra-distinction to classical Crohn's disease, which affects all coats of the bowel wall.

In the vast majority of cases on clinical and pathological grounds the two diseases can be dis $\frac{0}{T}$ tinguished from one another with little difficultyHowever, most authorities would agree that $\mathbb{Q} \mathbb{D}$ small percentage of patients cannot be allocated $\mathbb{\mathbb { D }}$ with confidence to either category; and perhap $\overline{0}$ for the moment whilst this difficult problem if $\mathbb{\complement}$ unresolved these occasional few cases would be $\overrightarrow{0}$ the best categorized as 'unclassifiable colitis'.

\section{Natural history}

The natural history of ulcerative colitis has provoked a number of important studies in the last 100 years, two of the most recent being those reported by Edwards \& Truelove from Oxford (1963) and that of our own group in Leeds (Watts et al., 1966a, b). From these studies it has emerged that the most logical way to deal with the course and prognosis of ulcerative colitis is initially to investigate the first attack of the disease suffered by the patient; and then to assess the long-term prognosis by a careful consideration of the subsequent course of the disease.

\section{First attack}

Since it is widely recognized that the first attack of ulcerative colitis is perhaps the most dangerous of all from the patient's point of view, it is astonishing that so little attention was paid to this important aspect of the disease prior to 1963 . Our own findings (Watts et al., 1966a) confirm those of Edwards \& Truelove (1963), namely that the factors which affect the outcome of the first attack are: 
(1) The severity of the attack.

(2) The extent of disease.

(3) The age of the patient.

The effect of these factors upon the mortality of our own patients during their first attack is shown in Fig. 1.

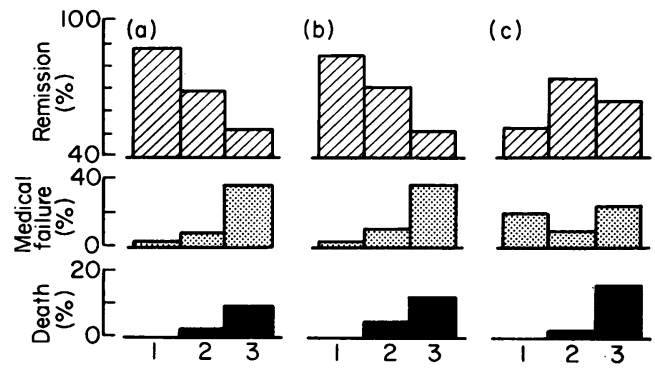

FIG. 1. The factors which modify the outcome of the first attack of ulcerative colitis; (a) the severity of disease, (b) the extent of involvement, and (c) the age of the patient. Severity: 1 , mild; 2 , moderate; 3 , severe. Extent: 1, rectum; 2, substantial; 3, total. Age: 1, under 20;2, 20-59; 3, over 60. (From Watts et al., 1966a.)

These findings in our own patients, covering the period 1952-63, emphasized that despite recent improvements in treatment, severe attacks of colitis, (particularly in those with extensive disease, or in those aged over 60 at the time), remained a formidable clinical problem with a high mortality. We, therefore, decided in 1964, as a result of our studies, that we would in future invoke the aid of radical surgery at an early stage of all severe attacks (including first attacks), unless there was unequivocal evidence of rapid improvement upon a conservative regime. A more recent publication (Goligher et al., 1967) has shown considerable initial success for this policy. No patient has died in a first attack of ulcerative colitis since 1963 ; and the overall mortality in all severe attacks of the disease (assessed according to the criteria of Truelove \& Witts, 1955) has been only $1.3 \%$ as against $11.3 \%$ in the previous decade.

In summary it may be fairly said, therefore, that there is a large measure of agreement concerning the initial attack of colitis. The mortality is highest during severe attacks, with extensive disease, and in elderly patients ; and this mortality may be sharply reduced by the early use of surgery where intensive medical treatment fails to produce an improvement.

\section{Subsequent course and long term prognosis}

Edwards \& Truelove (1963) claimed that the influence of the first attack of colitis extended throughout the course of the disease-in that those with severe initial attacks and total initial involvement subsequently tended to fare badly. In view of this we also attempted to relate the subsequent course of disease to the initial severity and extent of colitis; but it soon became apparent that in our patients what really influenced the subsequent prognosis in each individual patient during each year of followup was the severity and extent of involvement at that time. Our own results are summarized in Fig. 2. This shows the factors which modify the outcome (after the first referred attack) for each individual patient in each year of their disease. The marked ill effect of severe attacks, total involvement, and old age on the overall mortality can be well seen.

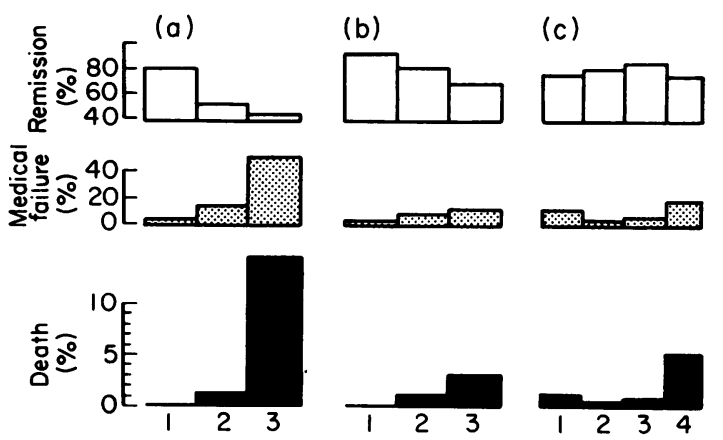

Fig. 2. The factors which modify the outcome of ulcerative colitis in each year after the first attack is over: (a) the severity and (b) extent of disease, and (c) age of the patient at the time (see Fig. 1). Age: $1,0-19 ; 2,20-39 ; 3,40-59 ; 4,60-79$. (From Watts et al., 1966b.)

\section{High-risk patients}

We have already dealt with patients who suffer from severe attacks of ulcerative colitis, and have commented that these severe attacks are best treated by radical surgery at an early stage. Our studies have also taught us, however, that patients with total colonic involvement are at a considerable risk; the mortality from the effects of the disease in such patients being less than $2.7 \%$ in each year of individual follow-up. This applies not only to patients with total involvement during but also to any patient who may develop total involvement during the subsequent course of their disease. Moreover (see p. 711), there is considerable evidence that this high cumulative mortality in patients with total involvement may be reduced by the use in such patients of elective proctocolectomy. Since our studies have shown that half such patients come to surgery anyway, many of them in desperate straits, it is not unreasonable to argue that it would be better to 
bring all of them to surgery at a time when they are relatively fit. Certainly the results of such a policy (see p. 711) would seem at this early stage to bear out such a contention.

\section{Conclusions}

To sum up, ulcerative colitis is always likely to re-assert itself at any time after the first attack is over, but in any large group of colitic patients just over half spend each year in remission. The initial severity and extent of colitis give a poor guide to subsequent prognosis (partly because the disease shows a tendency to extend proximally with the passage of time in many patients). Further analysis shows, however, that the severity and extent in the individual patient at any particular time profoundly influence the course and outcome of disease during that year. In our own group of patients those with total involvement carry a risk to life of around $3 \%$ each year-and this mortality could almost certainly be cut sharply by the use of elective proctocolectomy for all patients with total involvement.

\section{Local complications}

The complications of ulcerative colitis are bewildering in their complexity; and it was necessary as early as 1954 for Brooke to subdivide these into 'local' and 'systemic' complications. Local complications are those which are directly related to the pathological changes in the bowel; and a list of these local complications together with their frequency in our own group of 465 patients in Leeds is shown in Table 3. Once again these fascinating complications merit detailed individual study which is clearly not feasible within the present context. However, it may be appropriate to say a few words about two of the most lethal complications-namely perforation of the colon and large bowel cancer.

\section{TABLE 3}

Local complications of ulcerative colitis

\begin{tabular}{|c|c|c|}
\hline $\begin{array}{l}\text { Ano-rectal complications } \\
\text { (a) Abscess } \\
\text { (b) Fistula in ano } \\
\text { (c) Recto Vaginal fistula } \\
\text { (d) Fissue in ano }\end{array}$ & $\begin{array}{r}6.0 \% \\
5.4 \% \\
2.2 \% \\
12.3 \%\end{array}$ & $17 \cdot 6 \%$ \\
\hline $\begin{array}{l}\text { Pseudopolyposis } \\
\text { Stricture } \\
\text { 'Toxic megacolon' } \\
\text { Perforation } \\
\text { Carcinoma } \\
\text { Massive haemorrhage }\end{array}$ & & $\begin{array}{r}12.5 \% \\
11.2 \% \\
3.0 \% \\
2.8 \% \\
1.7 \% \\
1.5 \%\end{array}$ \\
\hline
\end{tabular}

*Percentage incidence is that found in 465 Leeds patients 1963 series).
Perforation of the colon

Intraperitoneal perforation of the colon is without a doubt the most lethal complication of

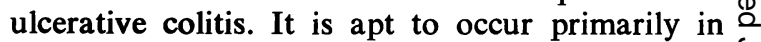
the first attack of the disease. In patients with severe first attacks and/or total colonic involve- $\overrightarrow{\vec{p}}$ ment, the risk of intraperitoneal perforation is about 15-20\% (de Dombal et al., 1965). Such perforations in our own experience are most likely to occur in the sigmoid colon.

Considerable controversy has raged concerning the influence of corticosteroid therapy on the $\mathrm{c}$ development of perforations in the colitic patient. $\vec{O}$ Many authorities, such as Bargen (1955) and Brooke (1956) are of the opinion that corticosteroid therapy predisposes in some way to the development of colonic perforation. However, our own experience is contrary to this; for the overall incidence of perforation in all severe attacks of the disease seem to be around $4 \%$ whether or not corticosteroids are used.

The treatment of established perforation is undoubtedly emergency colectomy; for whereas ? without such a procedure the mortality mas reach $100 \%$ (Jankelson, McClure \& Sweetsic \& 1945), the mortality after emergency colectom $\frac{8}{0}$ even in these desperate circumstances is usualle $\mathbb{D}$ somewhat less than $25 \%$ (de Dombal et al., 1965) Nonetheless, whilst it is true to say that estab 8 을 lished perforation is best treated by surgery, it is $\overrightarrow{0}$ often untrue to say that it is an indication fos. surgery, since established perforation is exceed ingly difficult to diagnose in the acutely ill colitic patient. Frequently a perforation of the colon presents not with the classical clinical picture of the silent, tender, rigid abdomen, but with a more general picture of catastrophe, the patient's general condition rapidly deteriorating despite intensive treatment. For this reason sudden deterioration of a patient during a severe attack - despite intensive treatment-is in our view an indication for emergency surgery.

\section{Large bowel cancer}

Recent studies (Edwards \& Truelove, 1964; MacDougall, 1964 ; de Dombal et al., 1966 ; Hinton, 1966); have emphasized that in patients with total or near-total colonic involvement by ulcerative colitis, the risk of development of large bowel cancer is indeed a serious one. Our own studies have enabled us to make some sort of quantitative assessment of the cancer risk in these patients (Figs. 3 and 4). The annual risk even in patients with total involvement of the large bowel by colitis is small during the first 10 years of their disease (Fig. 3) ; but after that it begins to rise alarmingly until after 20 years of bowel 
symptoms the annual cancer risk is no less than $6 \%$. Moreover this $6 \%$ is an annual risk; and if the risk over a period of 20,25 or 30 years is estimated, we find (Fig. 4) that this cumulative risk in patients with total involvement over a period of 30 years is no less than $56 \%$ ! Such a disturbing finding underlines the remarks made previously about the need for prophylactic surgery in patients with total involvement; for it shows that not only do they face risks which are serious enough in all conscience from their colitis, but in addition nearly half of such patients can be expected to develop large bowel cancer whilst still at a relatively young age.

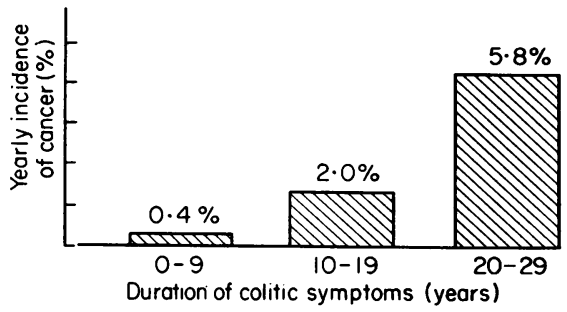

FIG. 3. The yearly incidence of large bowel cancer in 210 patients with total or near total involvement, related to the duration of colitic symptoms. (From de Dombal et al., 1966.)

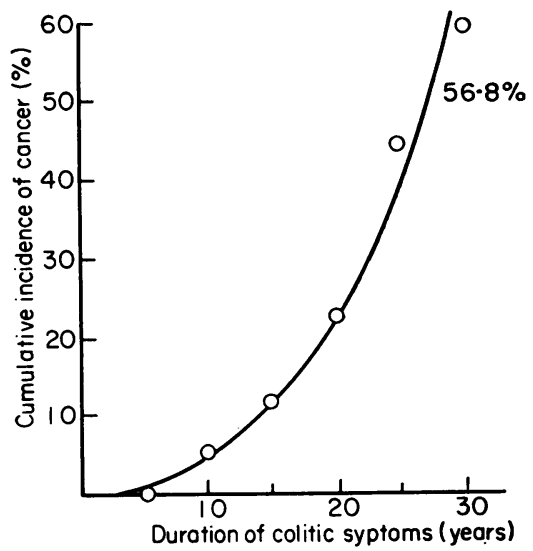

FIG. 4. The cumulative expected incidence of large bowel cancer over 30 years in patients with total involvement by colitis. (From de Dombal et al., 1966.)

\section{References}

Acheson, E.D. \& Truelove, S.C. (1961) Early weaning in the aetiology of ulcerative colitis. A study of feeding in infancy in cases and controls. Brit. med. J. ii, 929.

Allchin, W.H. (1885) A case of extensive ulceration of the colon. Trans. path. Soc. Lond. 36, 199.

ANDRESEN, A.F.R. (1925) Gastrointestinal manifestations of food allergy. Med. J. Rec. 122, 271.

ANDRESEN, A.F.R. (1942) Ulcerative colitis-an allergic phenomenon. Amer. J. dig. Dis. 9, 91.
Aretaeus (ca. A.D. 300) On the causes and symptoms of chronic diseases.

BARClAy, A.E. (1933) The Digestive Tract: A Radiological Study of its Anatomy, Physiology and Pathology. Cambridge University Press.

BARGEN, J.A. (1924) Experimental studies on etiology of chronic ulcerative colitis. J. Amer. med. Ass. 83, 332.

BARgen, J.A. (1955) Present status of hormonal and drug therapy of ulcerative colitis. Sth med. J. (Bgham, Ala.), 48, 2.

BARGen, J.A. (1966) Panel discussion: Symposium newer biological concepts in ulcerative colitis and related diseases. Gastroenterology, 51, 806.

Bicks, R.O. \& RosenberG. E.W. (1964) A chronic delayed hypersensitivity reaction in the guinea pig colon. Gastroenterology, 46, 543.

Broberger, O. \& Perlmann, P. (1959) Autoantibodies in human ulcerative colitis. J. exp. Med. 110, 657.

Brooke, B.N. (1954) Ulcerative Colitis and its Surgical Treatment. Livingstone, London.

BrooKe, B.N. (1956) The outcome of surgery for ulcerative colitis. Lancet, ii, 532.

CoRnelis, W. (1958) Quoted by Kraft, Bregman \& Kirsner (1962).

Crane, A.W. (1927) Amer. J. Roent. 17, 416. Quoted by Barclay (1933).

CroHn, B.B. (1962) An historic note on ulcerative colitis. Gastroenterology, 42, 366.

DE Dombal, F.T. (1967) Serum proteins in ulcerative colitis: levels in the inferior mesenteric artery and vein. Gut, $8,482$.

de Dombal, F.T., Watts, J.McK., Watkinson, G. \& Goligher, J.C. (1965) Intraperitoneal perforation of the colon in ulcerative colitis. Proc. roy. Soc. Med. 58, 713.

DE Dombal, F.T., WatTs, J.McK., WatKinson, G. \& Goligher, J.C. (1966) Local complications of ulcerative colitis: stricture, pseudopolyposis and carcinoma of the colon and rectum. Brit. med. J. i, 1442.

de Dombal, F.T., Darnborough, A., Geffen, N., WatKINSON, G. \& Goligher, J.C. (1968) The radiological signs of ulcerative colitis: an evaluation of their clinical significance. Gut, 9, 157.

DragstedT, L.R., DACK, G.M. \& KIRSNER, J.B. (1941) Chronic ulcerative colitis: bacterium necrophorum as etiologic agent. Ann. Surg. 114, 653.

DudeK, B., SPIRo, H.M. \& ThaYer, W.R., Jr (1965) A study of ulcerative colitis and circulating antibodies to milk proteins. Gastroenterology, 48, 544.

EDwards, F.C. \& Truelove, S.C. (1963) The course and prognosis of ulcerative colitis. I and II. Gut, 4, 299.

EdWards, F.C. \& Truelove, S.C. (1964) The course and prognosis of ulcerative colitis. III and IV. Gut, 5,1 .

EvANS, J.G. \& ACHeson, E.D. (1965) An epidemiological study of ulcerative colitis and regional enteritis in the Oxford area. Gut, 6, 311.

Feldman, F., Cantor, D., Soll, S. \& Bachrach, W. (1967) Psychiatric study of a consecutive series of 34 patients with ulcerative colitis. Brit. med. J. ii, 14.

Fink, S., Donnelly, W.J. \& Jablokow, V.R. (1967) Rectal reaction to injected ulcerative colitis: leucocytes and plasma. Gut, 8, 20.

FrADKIN, W.Z. (1937) Ulcerative colitis: bacteriological aspects. N.Y.Med. 37, 249.

Geffen, N., Darnborough, A., De Dombal, F.T., WatKINSON, G. \& Goligher, J.C. (1968) The radiological appearances of ulcerative colitis: an evaluation of their reliability by means of observer variation studies. Gut, 9, 150.

Glass, G.B.J., Pugh, B.L., Grace, W.J. \& Wolf, S. (1950) Treatment of human gastric and colonic mucus with lysozyme. J. clin. Invest. 29, 12. 
Goligher, J.C., De Dombal, F.T., Graham, N.G. \& WATKINSON, G. (1967) Early surgery in the treatment of severe attacks of ulcerative colitis. Brit. med. J. ii, 193.

Grace, W.J., Wolf, S. \& WolfF, H.G. (1951) The Human Colon. Heinemann, London; Hoeber, New York.

HALE-WhITE, W. (1888) On simple ulcerative colitis and other intestinal ulcers. Guy's Hosp. Rep. 45, 131.

HARRISON, W.J. (1965) Autoantibodies against intestinal and gastric mucous cells in ulcerative colitis. Lancet, i, 1346.

Henderson, R.G., Pinkerton, H. \& Moore, L.T. (1942) Histoplasma capsulation as a cause of chronic ulcerative colitis. J. Amer. med. Ass. 118, 885.

Hinton, J.M. (1966) Carcinoma in ulcerative colitis. Proc. roy. Soc. Med. 59, 632.

Jankelson, I.R., McClure, C.W. \& SweetsiR, F. (1945) Idiopathic ulcerative colitis: perforation of the bowel. Rev. Gastroent. 12, 31.

Kraft, S.C., Bregman, E. \& Kirsner, J.B. (1962) Criteria for evaluating autoimmune phenomena in ulcerative colitis. Gastroenterology, 43, 330.

MacDougall, I.P.M. (1964) The cancer risk in ulcerative colitis. Lancet, ii, 655.

Matrs, S.G.F. (1961) The value of rectal biopsy in the diagnosis of ulcerative colitis. Quart. J. Med. 30, 393.

MetTler, C.C. (1947) History of Medicine. Blakiston. Philadelphia \& Toronto.

Meyer, K., Gellhorn, A. \& Prudden, J.F. (1947) Lysozyme in chronic ulcerative colitis. Proc. Soc. exp. Biol. (N.Y.), 65, 221.

Morson, B. (1968) Ulcerative Colitis (Ed. by J.C. Goligher, F.T. de Dombal, J.McK. Watts and G. Watkinson). Bailliere, Tindall \& Cassell, London.

PerlmanN, P. \& Broberger, O. (1963) In vitro studies of ulcerative colitis. II. Cytotoxic action of white blood cells from patients on human fetal colon cells. $J$. exp. Biol. 117, 717.

ROSENBERG, E.W. \& Fischer, R.W. (1964) DNCB allergy in the guinea pig colon. Arch. Derm. 89, 99.

SORANUS OF EPHESUS (ca. A.D. 117) Quoted by Mettler (1947).
Stierlin, E. (1912) Zur röntgendiagnostik der colitis ulcerosa. Z. klin. Med. 75, 486.

TAYloR, K.B. \& Truelove, S.C. (1961) Circulating antibodies to milk proteins in ulcerative colitis. Brit. med. J. ii, 924.

Truelove, S.C. (1961) Ulcerative colitis provoked by milk. Brit. med. J. ii, 154.

Truelove, S.C. \& WITTS, L.J. (1955) Cortisone in ulcerative colitis. Brit. med. J. ii, 1041.

Victor, R.G., Kirsner, J.B. \& Palmer, W.L. (1950) Failure to induce ulcerative colitis experimentally with filtrates of feces and rectal mucosa. Gastroenterology, 14, 398.

Watson, D.W., Quigley, A. \& Bolt, R.L. (1966) Effect of lymphocytes from patients with ulcerative colitis on human adult colon epithelial cells. Gastroenterology, 51, 985.

WatTS, J.McK., DE Dombal, F.T., Watkinson, G. \& Goligher, J.C. (1966a) The early course of ulcerative colitis. Gut, 7, 16

WatTS, J.McK., DE DOMBal, F.T., WatKinson, G. \& Goligher, J.C. (1966b) The long term prognosis of ulcerative colitis. Brit. med. J. i, 1447.

WaTts, J.McK., Thompson, H. \& Goligher, J.C. (1966c) Sigmoidoscopy and cytology in the detection of microscopic disease of the rectal mucosa in ulcerative colitis. Gut, 7, 288.

Wilks, Sir SAmuel (1859) The morbid appearance of the intestine of Miss Banks. Medical Times and Gazette, 2, 264. Quoted by Crohn (1962).

Wilks, S. \& Moxon, W. (1875) Lectures on Pathological Anatomy, 2nd edn, pp. 408-672. Churchill, London.

Wilson, P.J.E. (1961) The Young Pretender. Brit. med. J. ii, 1226.

Wright, R. \& TRuelove, S.C. (1965a) A controlled thera peutic trial of various diets in ulcerative colitis. Brit. med. J. ii, 138.

Wright, R. \& Truelove, S.C. (1965b) Circulating antibodies to dietary proteins in ulcerative colitis. Brit. med.c̄e J. ii, 142.

Wright, R. \& TRUelove S.C. (1966) Auto-immune reactions in ulcerative colitis. Gut, 7, 32. 